\title{
Smart Mobility: Opportunities and Challenges for Colombian Cities
}

\author{
Erika Quiroga ${ }^{*}$, Karen Gutiérrez \\ Facultad Tecnológica, Universidad Distrital Francisco José de Caldas, Bogotá, 110111, Colombia
}

\begin{tabular}{l} 
A R T I C L E I N F O \\
\hline Article history: \\
Received: 04 May, 2021 \\
Accepted: 06 June, 2021 \\
Online: 15 June, 2021 \\
\hline Keywords: \\
Intelligent mobility \\
Intelligent Transport System \\
V2X communications \\
5G networks \\
Autonomous and connected \\
vehicles
\end{tabular}

\begin{abstract}
A B S T R A C T
The following document analyzes the current situation in mobility and intelligent transportation in Colombia and in some cities around the world. Presenting several cases of success and implementation of technologies and protocols that seek to improve the problems with the greatest impact in today's cities, such as traffic congestion, environmental impact, accessibility, and road safety. The main objective of this research is to propose recommendations appropriate for transportation systems in Colombian cities, identifying the present challenges; therefore, through this article we will expand the panorama on ITS (Intelligent Transport System) that can be developed taking into account the needs of each territory; optimizing the strategies proposed and in turn considering the solutions that are being carried out; taking them as a guide for cities that are still in search of better mobility plans.
\end{abstract}

\section{Introduction}

A UN study, with demographic data shows a population growth in urban areas, where it is estimated that $68 \%$ of the inhabitants will be located in cities by 2050 [1], this will occur mainly in developing countries due to the poverty rate that exists and that presents a prolonged increase. In addition, due to the increase in population, cities have had to transform the way they use their resources and start looking for technological alternatives. This idea has made the government, industry and society adopt the term Smart Cities [2].

A smart city is one that is concerned with the integration of all the factors that make up society; combining technology and organizational work to plan, optimize and monitor the resources, services and infrastructure available, offering its citizens wellbeing, sustainability and quality of life [3]. At the same time, a city can be called smart as long as ingenious ideas are developed that allow the growth of certain elements or pillars such as economyproductivity and labor market, mobility-transportation and infrastructure, surroundings-environment, people-level of qualification, life-living conditions and, governance-city management [4]. According to the above, it is determined that for the study of this article only one of the pillars that make up the

${ }^{*}$ Corresponding Author: Erika Quiroga, Facultad Tecnológica, Universidad Distrital Francisco José de Caldas, Bogotá, Colombia, ejquirogac@correo.udistrital.edu.co smart cities, smart mobility, will be taken; since it is considered a crucial factor in the development of cities and requires an analysis in the current scenario.

Considering the above, a smart city must be connected and automated in such a way that all its basic elements can become a whole. The energy is the main source for such connection, being the center of connectivity, communication and information [2]. The International Electrotechnical Commission (IEC) is responsible for standardization in the field of electricity, energy and other electrical and electronic components, therefore, focusing on smart cities formed an IEC Systems Committee [5] of electrotechnical aspects called SYC (Systems Committee), which delves into the Sustainable Development Goal for cities, controlling the implementation of new technologies, in addition to monitoring compliance with current regulations.

Mobility has been a challenge for cities around the world due to the different problems present in this environment, traffic congestion, deterioration of road infrastructure, accidents, gas and noise generation [6] are just some examples. This is why developed cities have worked to find technological solutions such as the implementation of IoT, Big Data, automated, hybrid or electronic vehicles [7], converting conventional transport into intelligent transport, optimizing and improving the quality of service for citizens [8]. A specific case is the European Union, 
that is constantly working on investment projects for the construction of smart cities [9], in total they have developed 81 projects, 70 have already culminated and 11 are still ongoing, of which 33 have addressed issues in mobility and transport [10].

On the other hand, in Latin America, public transportation is one of the most used mobility alternatives, where trips can be short in distance, but long in time; so alternatives such as Bus Rapid Transit (BRT), train systems, subways or cable cars are sought [11]. It should also be mentioned that studies have been conducted in the region that show the dissatisfaction of citizens; in terms of quality, time, comfort, safety, and cleanliness of transportation services, which is why many people have decided to purchase their own vehicles. However, this increase has caused greater traffic jams and congestion in cities [12]. Thus, road infrastructures in this region are not adequate for the number of vehicles moving in them; traffic control systems in many cases fail or are non-existences in these cities.

The current situation in Colombia is no different from the current scenario in Latin America; the dissatisfaction with transportation services is evident and therefore solutions are being sought in the country to reduce the impact on mobility in different cities. However, these technologies have not been successful because the systems are not adapted to the real situation of the place; the integration of services and their compatibility is not feasible and their implementation is complex [13].

Therefore, the development of this article will focus on the approach of recommendations suitable for Colombian cities. Identifying and analyzing technologies and communication protocols; that are currently used in different cities around the world, who are working to bring their transportation systems within the framework of intelligent mobility. Added to this, it is intended to show the current situation in Colombia and the aspects that should be strengthened.

\section{Methodology}

In the research of this article, information will be taken from different academic, organizational, and state sources of the last years; that will allow to build a real vision of the intelligent mobility scenario, mentioning the technological trends and protocols that make more efficient the management and control of traffic. Therefore, in order to formulate the necessary recommendations, the following step-by-step is determined to be used in the analysis of the document; P1: Make a description of the classification of the best countries in the world in mobility and intelligent transportation; P2: Define the essential factors in the measurement of the performance of the chosen pillar; P3: Identification of current technologies and infrastructures that are being developed and implemented around the world, mentioning some examples; P4: Description of the situation in Colombia recognizing the technologies used; P5: Formulate the appropriate recommendations in the country.

\section{Analysis and development}

In the study conducted by the IESE Business School of the University of Navarra in its report Cities in Motion 2020, a ranking is made among 174 cities around the world where nine (9) dimensions are evaluated among which are the mobility and transportation, in the top 10 of mobility the city that ranks first is New York (United States), followed by Paris (France) and London (United Kingdom) as shown in Table 1 [14]. It is evident that the regions that occupy the first places in smart mobility in the world are cities belonging to developed countries; that are constantly working to improve their indicators and it is precisely these three cities that led the overall ranking, being considered the smartest cities in the world.

Table 1: Ranking of the world's best cities in Mobility and Transportation.

\begin{tabular}{|c|c|c|}
\hline Position & City & Country \\
\hline 1 & New York & United States \\
\hline 2 & Paris & France \\
\hline 3 & London & United Kingdom \\
\hline 4 & Berlin & Germany \\
\hline 5 & Madrid & Spain \\
\hline 6 & Munich & Germany \\
\hline 7 & Vienna & Austria \\
\hline 8 & Beijing & China \\
\hline 9 & Barcelona & Spain \\
\hline 10 & Shanghai & China \\
\hline \multicolumn{2}{|c|}{ Own elaboration - Data taken from [14]. } \\
\hline
\end{tabular}

In turn, the factors that are evaluated to measure the performance of smart mobility in a city are determinants, such elements are public transport, accessibility, connectivity and road network [15], as shown in Figure 1. In this graph, three categories are described that intend to deploy the thematic for a better understanding; in the first place, there is the dimension or pillar Mobility and Intelligent Transport that is the basis of the analysis; from this level arise some ramifications called factors that are the aspects where the main needs and demands of today's cities are found, which is why it is of utmost importance to have indicators that allow evaluating the growth or performance of those strategies implemented to improve transportation systems.

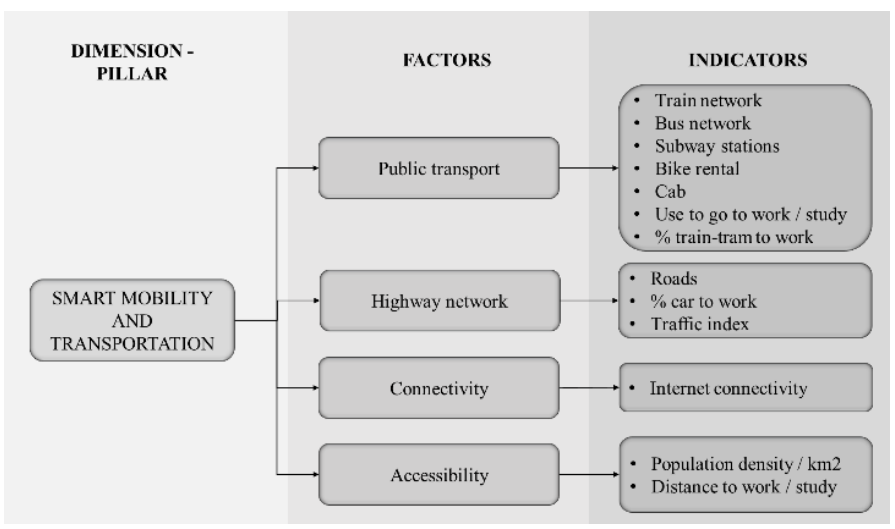

Figure 1: Intelligent mobility factors and indices [14], [15]. 
It is necessary to mention that the indicators may vary according to the population since cities have different needs and as a result their indexes also change; establishing unique objectives and measures to strengthen the transportation systems for each territory.

An example of these indexes is New York; a city that has implemented several transportation alternatives for its inhabitants, for this reason, some indicators have been defined, such as the following:

- \# Of metro/bus passengers: 2.5 billion passengers/year. 7.5\% increase since 2010.

- \# Of bicycle trips (City Bike): 30,000 Trips/day (2016-2017 record).

- \# Of passengers by Ferry: Grew, 4,000 trips/day (2016-2017 record).

- $\%$ Of trips per application: $90 \%$ increase since 2010.

- $\%$ Of vehicle registrations for rental: $22.7 \%$ increase (20162017 registration).

- $\%$ Of sustainable mode trips: $61.4 \%$ of total trips reported [16].

According to the above information, these indicators are related to the factors of public transportation and accessibility. The city government has focused its efforts on creating a diversified system; that facilitates the mobility of the population, while offering a portfolio of optimal possibilities that meet the needs of the user. Likewise, it can be observed that the results obtained in the last decade in NY were positive; since many of its indicators are in constant growth, allowing no means of transportation to collapse due to demand.

\section{ITS- V2X Communications}

A possible solution is found in ITS (Intelligent Transport Systems) which provide innovative alternatives through communication networks called V2X where all actors can exchange information with each other. These communications will allow better safety and traffic management; reducing accidents, gas emissions, improving vehicle flow at intersections or roads and in turn facilitating the use of autonomous and connected vehicles [17] which is the main means where this technology is applied.

In these networks there are four types of connection as shown in Figure 2, the first case, V2V (Vehicle-to-Vehicle) occurs in cars that being in motion communicate directly with other cars, in the case of V2I (Vehicle-to-Infrastructure) communication occurs when the vehicle is connected to the road infrastructure such as. In the case of V2P (Vehicle-to-Pedestrian) the connection is between cars and people who have a compatible device, and finally there is the case of V2N (Vehicle-to-Network) where the communication occurs when the car connects to the mobile network or available data networks [18].

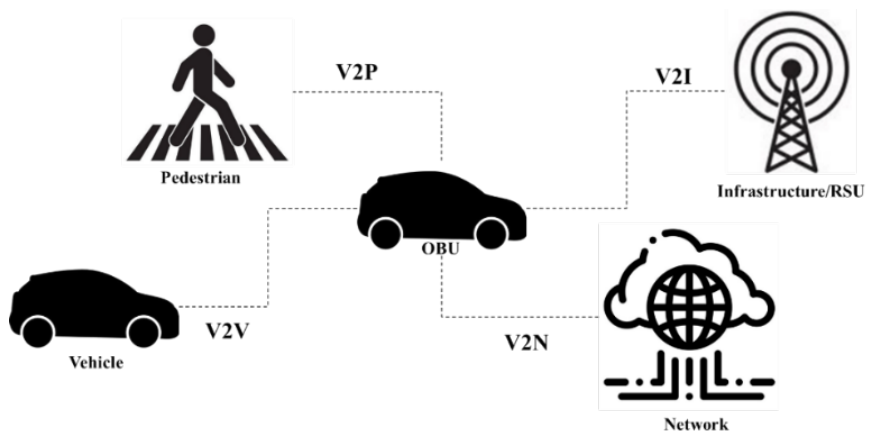

Figure 2: Connection types.

For these communications to be possible, two main technologies have been established, the first is DSRC (Dedicated Short Range Communications) defined for the United States and the second C-ITS or ITS-G5 specified for Europe, based on the first generation IEEE $802.11 \mathrm{p}$ standard, with which multiple tests have been performed in V2X communications [19]. However, with the scientific advances of recent years, better alternatives have been sought to develop different technologies, so a new standard called LTE-V2X was created, and its technology is called $\mathrm{C}-\mathrm{V} 2 \mathrm{X}$, which is understood as cellular communication from vehicle to everything.

In DSRC and ITS-G5 technology, communication is possible by means of devices installed on the road that is responsible for exchanging information, among which are the so-called OBU (On Board Unit) devices that are located in vehicles and the RSU (Road Side Unit), which as its name suggests, are those devices that are located on the road [20]. Similarly, C-V2X technology is based on several technologies that have reached their maturity point, but will have greater difficulty in the transition to $5 \mathrm{G}$ networks, so using the current LTE standard enables communication between different users in mobility and can be executed in 5G mobile networks in the coming years [17].

For this reason, $5 \mathrm{G}$ networks are suitable for the creation of ITS through the use of small cells or macro cells; that will facilitate the exchange of information in a more agile way between existing types of communication; processing a large amount of data simultaneously coming from different devices avoiding background traffic [21]. This technology also has three key functions, the first is eMBB (enhanced Mobile Broadband) that offers a stable connection transmitting data at high-speed maintaining good communication in long periods of time, the second service URLLC (Ultra Reliable Low Latency Communications) data transmission is reliable. Finally, there is the mMTC (massive Machine Type Communications) case where a certain amount of data can be transmitted using fixed speed, connecting multiple IoT devices that are occasionally linked without collapsing the network [22].

\subsection{Implementation cases.}

Currently, projects or pilots based on the above-mentioned communication technologies, such as INFRAMIX [23], 5G 
MOBIX, 5G CARMEN [24] and AUTO C-ITS, are being developed in several countries of the European Union.

\section{- INFRAMIX}

Project that seeks to improve the physical and digital road infrastructure of cities; through strategies that allow the analysis, road safety, traffic, and user satisfaction, monitoring and proper control of the system. Therefore, pilot tests have been launched in two countries, Spain, and Australia.

In both cases a $20 \mathrm{~km}$ segment of road was taken, equipped with different devices such as sensors, surveillance cameras, Bluetooth antennas, weather stations, using C-ITS-G5 and short range communications in which the V2I type predominates; at the same time traffic signs, RSU (control stations) and OBU (portable devices) were installed with which it was possible to exchange information throwing suggestions of lane or speed changes; the whole system was tested using 4G networks [25][26].

\section{- $5 G-M O B I X$}

This is a project that seeks to test and develop the functionality of vehicles through technologies that focus on $5 \mathrm{G}$ networks, through the construction of cross-border corridors and tests in urban sites in different countries of the European Union, analyzing network coverage, demand for services and vehicular traffic.

Among the test sites are: (a) The Netherlands specifically in Brain port where combined road networks have been built, installing C-ITS technologies at intersections and at the same time fully equipping a six (6) km highway with surveillance cameras and C-ITS. These technologies when connected to 5G will manage to leverage the information collected on the road and in vehicles, renewing functions to prevention and automated driving [27]. (b) China-Jinan, this test site has two main roads equipped with LTE-V infrastructure and V2X-5G communications; suitable to prevention, automated overtaking, traffic efficiency and road safety evaluations [28].

\section{- $5 G C A R M E N$}

This project focuses on innovation to develop a hybrid network that integrates different types of communications such as long-range V2N, V2X and short-range V2I, through technologies such as $\mathrm{C}-\mathrm{V} 2 \mathrm{X}$ and $5 \mathrm{G}$ that can offer secure and cross-border services.

It is developed in the Bologna-Munich corridor with a section of $600 \mathrm{~km}$ distributed in three countries, its purpose is to take advantage of the progress made by $5 \mathrm{G}$ networks to improve the transport service making it safer, smarter and more environmentally friendly, thus offering a multi-tenant platform that can assist in mobility to this region [29].

\section{- $\quad A U T O C-I T S$}

This project aims to improve the interoperability of transport services in Europe by means of C-ITS technology to promote www.astesj.com autonomous driving; therefore, it was decided to carry out three pilots in: Madrid, Paris, and Lisbon, strategically located in the so-called Atlantic corridor. Table 2 describes the different characteristics of the projects, such as their communication channels, current traffic conditions and C-ITS services in the cities. It is worth noting that the city in which there has been a greater development in C-ITS technology is in Madrid, covering a wider road segment and installing a greater number of RSUs. It is possible that this benefits the test since the defined traffic conditions are a little more detailed than in the other pilots; in addition to obtaining a greater amount of valuable information on vehicular traffic through constant monitoring [30].

Table 2: AUTO C-ITS pilot projects.

\begin{tabular}{|c|c|c|c|}
\hline Pilot City. & Madrid - Spain. & $\begin{array}{l}\text { Lisboan. - } \\
\text { Portugal. }\end{array}$ & $\begin{array}{l}\text { Paris - } \\
\text { France. }\end{array}$ \\
\hline Road. & $\begin{array}{l}\text { A6 autovía del } \\
\text { Noroeste, high } \\
\text { occupancy } \\
\text { reversible lane. }\end{array}$ & A9 CREL & $\begin{array}{l}\text { Highway } \\
\text { A13 }\end{array}$ \\
\hline Extension/ RSU & $\begin{array}{l}10 \mathrm{kms} \\
15 \mathrm{RSU} \\
\text { installed }\end{array}$ & $\begin{array}{l}7 \mathrm{kms} \\
\text { Installed } 5 \\
\text { RSUs }\end{array}$ & $\begin{array}{l}\text { Installed } 1 \\
\text { RSU }\end{array}$ \\
\hline $\begin{array}{c}\text { Traffic } \\
\text { conditions. }\end{array}$ & $\begin{array}{l}\text {-More than } \\
20,000 \\
\text { vehicles/day. } \\
\text {-Closed traffic: } \\
\text { Controlled tests. } \\
\text {-Open traffic: } \\
\text { Private vehicles } \\
\text { and collective } \\
\text { public transport } \\
\text { (bus). }\end{array}$ & $\begin{array}{l}\text {-Open peri- } \\
\text { urban traffic. } \\
\text {-Controlled } \\
\text { traffic } \\
\text { conditions. }\end{array}$ & $\begin{array}{l}\text {-Urban and } \\
\text { peri-urban } \\
\text { traffic. }\end{array}$ \\
\hline $\begin{array}{l}\text { Vehicles } \\
\text { involved. }\end{array}$ & $\begin{array}{l}\text {-Connected } \\
\text { vehicles: } 4 \\
\text {-Autonomous } \\
\text { vehicles: } 2\end{array}$ & $\begin{array}{l}\text {-Autonomous } \\
\text { vehicles: } 2 \\
\text {-Shuttle } \\
\text { autonomous: } 1 \\
\text {-Connected } \\
\text { vehicles: } 2\end{array}$ & $\begin{array}{l}\text { - } \\
\text { Autonomous } \\
\text { vehicles: } 1 \\
\text { C1 Evie } \\
\text {-Connected } \\
\text { vehicles: } 4 \\
\text { C3 }\end{array}$ \\
\hline $\begin{array}{c}\text { Communication } \\
\text { channel }\end{array}$ & ITS G5 & ITS G5 & ITS G5 \\
\hline Services C-ITS. & $\begin{array}{l}\text {-Road Works } \\
\text { information } \\
\text { service. } \\
\text {-Meteorological } \\
\text { information } \\
\text { service. } \\
\text {-Traffic Service } \\
\text { ahead. }\end{array}$ & $\begin{array}{l}\text {-Notification } \\
\text { of slow or } \\
\text { stopped } \\
\text { vehicles. } \\
- \\
\text { Meteorological } \\
\text { information } \\
\text { service. } \\
\text {-Other } \\
\text { dangerous } \\
\text { notifications. }\end{array}$ & $\begin{array}{l}\text {-Hazardous } \\
\text { location } \\
\text { notification. } \\
\text {-Contextual } \\
\text { speed } \\
\text { adaptation. } \\
\text {-Traffic } \\
\text { scheduling } \\
\text { assistant. }\end{array}$ \\
\hline
\end{tabular}

*Source: Own elaboration - Data taken from European Union [30]

\section{- $\quad$ VRUITS}

Similarly, there are some completed projects that have worked on ITS obtaining satisfactory results. One of these cases is the 
VRUITS project that was developed with the support of the European Union in the Netherlands and Spain; its objective was to improve the mobility and safety of the vulnerable road user or VRU (cyclists or pedestrians) and in turn provide recommendations to intelligent transport systems based on evidence to achieve a complete integration with VRU [31]. The test conducted in the Netherlands consisted of improving safety at intersections by monitoring cyclists and car drivers and sending alerts about possible collisions; through the installation of RSUs, $80 \%$ of all cyclists were detected and confirmed the safety of the system.

The first evaluated whether the implementation of sensorcontrolled traffic lights could optimize pedestrian mobility; the results showed that pedestrian waiting time was reduced by $20 \%$. In the second case, the initiative sought to improve visibility at the crosswalk, reducing by $5 \%$ the number of pedestrians crossing at red lights, thereby increasing pedestrian safety.

\section{Situation in Colombia}

In Colombia, transportation has presented significant problems that deteriorate the mobility system in the different cities of the country, preventing its inhabitants from having a safe and quality service. Accident rate is one of these factors, only in 2019 there was a total of 6,826 deaths due to road accidents, of which $53.7 \%$ was motorcyclists, $25.6 \%$ pedestrians, $8.5 \%$ private vehicles and $6.3 \%$ cyclists [32]; the most affected departments were Antioquia, Valle del Cauca, Cundinamarca and Bogotá, in the latter it is estimated that every 5.6 minutes a simple collision or accident with injuries or death occurs [33].

Likewise, road congestion has become a critical point in mobility, according to the traffic index conducted by TomTom (company that annually monitors 57 countries, 416 cities in six (6) continents) Bogota was the third (3) most congested city in the world for 2019 with a congestion level of 68\%; a 30 Min trip could increase to $58 \mathrm{Min}$ in the morning and $63 \mathrm{Min}$ at night during the rush hour. By 2020 this congestion level decreased to 53\% due to the strict confinement that was presented by the sanitary emergency; however, the city remained in the third place in the world ranking becoming the most congested in Latin America [34].

Similarly, the number of automobiles greatly affects vehicular traffic, in recent years the vehicle fleet has increased considerably, according to the RUNT registry as of February 2021, a total of $16,176,803$ vehicles were registered nationwide [35], including motorcycles, cars, vans, trucks, buses, among others; a number that continues to increase since it is optimal and convenient for citizens to purchase a vehicle rather than use public services.

Considering the above information, the government has devised some solutions to address part of the problems present in the transportation system of the country cities; for this reason, the Ministry of Transportation established a series of annual objectives to meet the ITS Project in the period 2015 - 2018. In this last year, the photodetection system was created and deployed throughout the country in order to monitor the speed of vehicles on the road and their violations [36]. Manual or automatic cameras are used to detect violations in image and video; operated by professionals from the control center to analyze the evidence obtained and validate it with the database of all cars registered in the cities [37].

Another of the ITS strategies was the implementation of the Vehicular Electronic Toll Collection systems, in this way electronic tolls were put into operation, managing to install 40 tolls in 2018. This system provides users with a unique onboard device, called TAG; which works with radiofrequency technology that allows them to make the relevant payments in an agile manner, avoiding lines and delays at the tolls [38]. Likewise, in 2019 in Bogota, smart traffic lights were installed at 21 intersections in the city to monitor and control vehicular traffic, obtaining realtime information on schedules and the number of vehicles transiting at these points, with the purpose of optimizing the light green time [39].

On the other hand, in 2020 there were already some fourth generation infrastructure projects (4G), including "safer tunnels" equipped with lighting, communication, fire detection and extinguishing systems; ventilation equipment, signaling and traffic light systems controlled from a command and control post [40]; these projects offer safety to the user, reduce environmental impact and ensure the stability of the work in the event of any catastrophe.

Finally, regarding communication networks, Colombia created the New Technologies Transition Plan, which aims to modernize the existing ones in the territory; Although in many urban areas $4 \mathrm{G}$ technologies have been successfully installed, there are still areas in the country where $2 \mathrm{G}$ and $3 \mathrm{G}$ communication networks are still in force, exactly 9.5 million Colombians and 34.3 million users do not have any mobile Internet connection [41], alarming figures for a country that discusses intelligent transportation systems; as a result of this, the aim is to achieve that before 2022 the whole country has access to a $4 \mathrm{G}$ network and can connect and communicate with the surrounding environment.

\section{Recommendations}

- It is evident that Colombia has failures in the deployment of mobile connections. Therefore, it is essential as a first step that $4 \mathrm{G}$ networks have a wide coverage throughout the territory providing secure and quality connectivity to the entire population. It is also necessary to create strategies that promote the use of these mobile networks in the cities; highlighting the variety of benefits that bring the connection to the mobile network.

- Likewise, it is necessary to carry out research and development on the technologies that are being implemented around the world; to create an adequate transportation system that is coherent with the particularities of the Colombian system. For this reason, the government plays a decisive role 
in the development of ITS strategies since financing is fundamental so that the projects do not remain ideal or halfway through.

- Considering that some of the country's problems are traffic and road accidents; cities in Colombia could consider a scenario with autonomous and connected vehicles integrated to the public and private sector; allowing to build a technological environment through an infrastructure equipped with sensors, cameras, signaling, RSU, OBU and $5 \mathrm{G}$ network, leading the country to an intelligent mobility.

- A V2N, V2V or V2I communication pilot for cities in Colombia could be the beginning of a real digital transformation. Which would allow an evaluation of functionality and data analysis of traffic, accident, or weather conditions, in a real environment in real-time, progressively integrating autonomous vehicles to the conventional structure of the country.

\section{Conclusions}

Although ITS plans and projects have been created in the country since 2015 , Colombian cities are not yet ready for the implementation of state-of-the-art technologies in this scenario, an example of this are their obsolete communication networks that would not allow a constant flow of large volumes of information without first collapsing. Therefore, talking about ITS is not only about sensors, cameras, or intelligent traffic lights, it is about building an interconnected environment where information is available to the user in real-time, allowing an efficient management of road resources to provide an appropriate service according to the needs of citizens.

In this way, countries such as Spain, France, the Netherlands, China, and Australia have made significant progress in intelligent mobility taking the lead in the implementation of V2X communication technologies, which for Colombia are still far away; however, this analysis was built to show the current panorama of these systems and identify the right way to build smart cities. Learning from the mentioned success cases, looking for a future implementation of ITS in the different cities of the country.

Colombia must continue working on the creation of intelligent transportation systems. Making incursions into the different available technologies mentioned in the article; building step-bystep strategies to build models like those seen today in the most developed countries in the world.

\section{Conflict of Interest}

The authors declare no conflict of interest.

\section{References}

[1] Z. Szabo, "The Effects of Globalization and Cyber Security on Smart Cities," Interdisciplinary Description of Complex Systems, 17(3), 503-510, 2019, doi:10.7906/indecs.17.3.10.

[2] International Electrotechnical Commission, Smart Cities, 2020, doi:10.1109/jproc.2018.2812998.
[3] Z. Allam, P. Newman, "Redefining the Smart City: Culture, Metabolism and Governance," Smart Cities, 1(1), 4-25, 2018, doi:10.3390/smartcities1010002.

[4] J. Winkowska, D. Szpilko, S. Pejić, "Smart city concept in the light of the literature review," Engineering Management in Production and Services, 11(2), 70-86, 2019, doi:10.2478/emj-2019-0012.

[5] International Electrotechnical Commission, SyC Smart Cities Electrotechnical aspects of Smart Cities, 2019.

[6] F. Behrendt, "Cycling the Smart and Sustainable City: Analyzing EC Policy Documents on Internet of Things, Mobility and Transport, and Smart Cities," Sustainability, 11(3), 763, 2019, doi:10.3390/su11030763.

[7] L. van Oers, E. de Hoop, E. Jolivet, S. Marvin, P. Späth, R. Raven, "The politics of smart expectations: Interrogating the knowledge claims of smart mobility," Futures, 122, 102604, 2020, doi:10.1016/j.futures.2020.102604.

[8] D. Bamwesigye, P. Hlavackova, "Analysis of Sustainable Transport for Smart Cities," Sustainability, 11(7), 2140, 2019, doi:10.3390/su11072140.

[9] A. Akande, P. Cabral, P. Gomes, S. Casteleyn, "The Lisbon ranking for smart sustainable cities in Europe," Sustainable Cities and Society, 44, 475487, 2019, doi:10.1016/j.scs.2018.10.009.

[10] European Commission, Projects | Smart Cities Marketplace.

[11] P. Yañez-Pagans, D. Martinez, O.A. Mitnik, L. Scholl, A. Vazquez, "Urban transport systems in Latin America and the Caribbean: lessons and challenges," Latin American Economic Review, 28(15), 1-25, 2019, doi:10.1186/s40503-019-0079-z.

[12] M.E. Rivas, A. Suárez-Alemán, T. Serebrisky, Stylized Urban Transportation Facts in Latin America and the Caribbean, 2019, doi: $10.18235 / 0001606$.

[13] R. Salazar-Cabrera, A. Pachon, "Methodology for Design of an Intelligent Transport System (ITS) Architecture for Intermediate Colombian City," INGENIERÍA Y COMPETITIVIDAD， 21(1), 49-62, 2019, doi:10.25100/iyc.v21i1.7654.

[14] IESE Businee School University of Navarra, IESE Cities in Motion Index 2020, 2020.

[15] M.A. Ur Rehman Tariq, A. Faumatu, M. Hussein, M.L. Ur Rahman Shahid, N. Muttil, "Smart city-ranking of major australian cities to achieve a smarter future," Sustainability (Switzerland), 12(7), 2797, 2020, doi:10.3390/su12072797.

[16] NYC Department of Transportation, Mobility Report, 2019.

[17] A. Costandoiu, M. Leba, "Convergence of V2X communication systems and next generation networks," IOP Conference Series: Materials Science and Engineering, 477(1), 012052, 2019, doi:10.1088/1757-899X/477/1/012052.

[18] GSMA, Espectro para Sistemas Inteligentes de Transporte Posición sobre políticas públicas de la GSMA, 2017.

[19] R. Molina-Masegosa, J. Gozalvez, M. Sepulcre, "Comparison of IEEE $802.11 \mathrm{p}$ and LTE-V2X: An Evaluation with Periodic and Aperiodic Messages of Constant and Variable Size," IEEE Access, 8, 121526-121548, 2020, doi:10.1109/ACCESS.2020.3007115.

[20] K. Kiela, V. Barzdenas, M. Jurgo, V. Macaitis, J. Rafanavicius, A. Vasjanov, L. Kladovscikov, R. Navickas, "Review of V2X-IoT Standards and Frameworks for ITS Applications," Applied Sciences, 10(12), 4314, 2020 , doi:10.3390/app10124314.

[21] H. U. Mustakim, "5G Vehicular Network for Smart Vehicles in Smart City: A Review," Journal of Computer, Electronic, and Telecommunication, 1(1), 2020, doi:10.52435/complete.vli1.44.

[22] P. Popovski, K.F. Trillingsgaard, O. Simeone, G. Durisi, "5G wireless network slicing for eMBB, URLLC, and mMTC: A communicationtheoretic view," IEEE Access, 6, 55765-55779, 2018, doi:10.1109/ACCESS.2018.2872781.

[23] P. Lytrivis, E. Papanikolaou, A. Amditis, M. Dirnwöber, A. Froetscher, R. Protzmann, W. Rom, A. Kerschbaumer, "Advances in Road Infrastructure, both Physical and Digital, for Mixed Vehicle Traffic Flows.," Proceedings of 7th Transport Research Arena, Viena, Australia, 1-10, 2018.

[24] A. Kousaridas, A. Schimpe, S. Euler, X. Vilajosana, M. Fallgren, G. Landi, F. Moscatelli, S. Barmpounakis, F. Vázquez-Gallego, R. Sedar, R. Silva, L. Dizambourg, S. Wendt, M. Muehleisen, K. Eckert, J. Härri, J. Alonso-Zarate, "5G Cross-Border Operation for Connected and Automated Mobility: Challenges and Solutions," Future Internet, 12(1), 5, 2019, doi:10.3390/fi12010005.

[25] INFRAMIX, Spanish test site - Inframix EU Project.

[26] INFRAMIX, Austrian test site - Inframix EU Project.

[27] European Commission, 5G-MOBIX - The Netherlands.

[28] European Commission, 5G-MOBIX - China.

[29] European Commission, About - 5G CARMEN.

[30] European Commission, AUTO C-ITS.

[31] European Commission, Moving in the right direction for the protection of 337 
vulnerable road users | Results In Brief | CORDIS | European Commission.

[32] Agencia Nacional de Seguridad Vial, Histórico víctimas | ANSV.

[33] Bogotá, Análisis de accidentes viales en Bogotá en 2019| Bogota.gov.co.

[34] TOMTOM, TomTom Traffic Index - Live congestion statistics and historical data.

[35] RUNT, Parque automotor registrado en RUNT | RUNT.

[36] Ministerio de Transporte, Proyectos ITS año 2018.

[37] Secretaria de Movilidad, CONOZCA LAS VÍAS DONDE SE UBICAN LAS CÁMARAS DE FOTODETECCIÓN DE INFRACCIONES QUE TIENE BOGOTÁ | Secretaría Distrital de Movilidad.

[38] Ministerio de Transporte, Peajes electrónicos - Ministerio de Transporte.

[39] Bogotá, Bogotá ya cuenta nuevos semáforos inteligentes | Bogota.gov.co.

[40] Agencia Nacional de Infraestructura, Túneles más seguros y eficientes en los proyectos $4 \mathrm{G} \mid$ Portal ANI.

[41] MinTIC, Colombia inicia transición de redes $2 \mathrm{G}$ y $3 \mathrm{G}$ hacia $4 \mathrm{G}$. 